\title{
The Potential Sources of Foreign Language Reading Anxiety in a Jordanian EFL Context: A Theoretical Framework
}

\author{
Ismail Sheikh Ahmad ${ }^{1}$, Murad M. Al-Shboul ${ }^{1}$, Mohamad Sahari Nordin ${ }^{1}$, Zainurin Abdul Rahman ${ }^{1}$, Mohd \\ Burhan $^{1} \&$ Kamal Basha Madarsha ${ }^{1}$ \\ ${ }^{1}$ Institute of Education, International Islamic University Malaysia, Malaysia \\ Correspondence: Murad M. Al-Shboul, Institute of Education, International Islamic University Malaysia, \\ Malaysia. E-mail: muradshboul@yahoo.com
}

Received: July 15, $2013 \quad$ Accepted: August 5, $2013 \quad$ Online Published: October 10, 2013
doi:10.5539/elt.v6n11p89 $\quad$ URL: http://dx.doi.org/10.5539/elt.v6n11p89

\begin{abstract}
The last decade has witnessed an increasing research trend on foreign language reading anxiety as a skill related to but distinct from foreign language anxiety. However, sources of foreign language reading anxiety have rarely been investigated. Thus, the current study responds to the study by (Saito, Horwitz, \& Garza, 1999) and extends the work of (Al-Shboul, Ahmad, Nordin, \& Rahman, 2013b) in this specific area to propose a theoretical framework that represents the sources of foreign language reading anxiety and to measure the extent of those sources in the Jordanian EFL context. A cross-sectional survey of 1500 undergraduate students who were taking Basic English courses was administered. A total of 1006 questionnaires were valid for analysis. However, only 408 questionnaires were randomly chosen according to the criteria of quota sampling techniques. The proposed theoretical framework was tested to measure the prevalence of the sources of foreign language reading anxiety to reveal that there were two aspects of foreign language reading anxiety: personal factors and text features. Under the concept of personal factors, there were two main sources of foreign language reading anxiety; afraid of making errors and worry about reading effects. On the other hand, there were three main sources of foreign language reading anxiety under the concept of text features; unknown vocabulary, unfamiliar topic, and unfamiliar culture. Implications to the study and recommendations for further research were considered.
\end{abstract}

Keywords: sources of foreign language reading anxiety, foreign language reading anxiety, Jordanian EFL Context, Yarmouk University, theoretical framework

\section{Introduction}

English language is the language of the contemporary knowledge. To access this knowledge, one must learn English. Thus, English language has become an international language. In fact, it is spoken by the majority of people around the world. Due to this fact, Kachru (1985) has classified English language into three categories. These categories explain that English language is used in different ways around the world. In other words, he has distinguished between English as a Native Language (ENL), English as Second Language (ESL), and English as a Foreign Language (EFL). According to Kachru, ENL refers to the countries where English is used as a primary language, as a mother tongue; these countries include USA, UK, Canada, Australia, and New Zealand. ESL refers to the countries where English is used as an official language and plays an important role as a second language but not the main language in a multilingual setting; some examples of these countries are Malaysia, India, and Nigeria. Finally, EFL refers to countries where English is taught as a foreign language. It is typically taught in schools at the classrooms as a subject. Therefore, students do not have the opportunity to use English outside the classrooms. Consequently, students are less motivated to learn the language. Some of these countries are: China, Japan, Korea, Taiwan, Poland, and Jordan, (Cited in Crystal, 2004; Kirkpatrick, 2007).

Jordan is one of the Middle East countries where English is used as a foreign language. It is taught in public and private schools, colleges, universities and other learning institutions. In fact, it is a required subject in all educational stages and recently has become a compulsory subject in the basic educational system starting from the first grade instead of fifth grade as it was before the academic year 2000/2001. In the universities, it is also a required subject in some fields of study, or it is a medium of instructions in some other fields of study. In both cases, learning English language is important for the students in order to access the modern-day knowledge. It gives an access to the new knowledge and enables us to communicate with researchers in the field to be in touch 
with the latest thinking and research (Crystal, 1997).

Studying at Yarmouk University, which is one of the public universities in Jordan, undergraduate students are most likely take two or three Basic English courses. These compulsory courses are named "Skill 101" and "Skill 102" while the pre-requisite basic English, which is named "Skill 100" is taken based on the result of the placement test. In these courses, the four language skills are taught; listening, speaking, reading and writing.

However, these courses are linked with problems; the majority of the students have expressed being anxious in learning the English language (Al-Shboul et al., 2013b). This language anxiety affects their learning process and their performance in general (Al-Shboul, Ahmad, Nordin, \& Rahman, 2013a). It is an obstacle that hinders the students from learning or acquiring foreign language (Horwitz, Horwitz, \& Cope, 1986).

Considering that English is used as a foreign language in Jordan, reading skill is the most important skill in order to achieve the modern-day knowledge. It is an important fundamental receptive skill student relies much on for the academic purposes in higher education, whether English is used as a medium of instruction, or it is used as a subject. This is because the reading skill is highly correlated to academic performance and to somewhat gaining the knowledge is based on reading.(Carrell, Devine, \& Eskey, 2000).

However, beginner foreign language learners often express a feeling of stress, nervousness or anxiety in learning a foreign language in general (Horwitz et al., 1986) and in reading skill as a specific skill as well (Saito, Horwitz, \& Garza, 1999). As a matter of fact, neuroscience reviewed research have found that nervousness associated with reading task truly exists (Jalongo \& Hirsh, 2010). This is often true among Jordanian students who learn English as a foreign language. The researcher's observation is that many of the students cannot understand English texts well albeit their efforts in understanding the reading materials (Al-Shboul et al., 2013b). Despite the students' ability in reading English, some anxieties affect their ability, and they find serious difficulties in reading academic English texts. Some students avoid activities in English reading classes, cutting the classes, postpone taking English courses until the last year, or at least they are not enthusiastic towards reading in English and in some cases they avoid reading English materials (Jalongo \& Hirsh, 2010). These manifestations are symptoms of foreign language anxiety in the classroom (Horwitz et al., 1986). Therefore, the main purpose of the current article is to propose a theoretical framework that represents the sources of foreign language reading anxiety in order to examine the extent of the sources in the Jordanian EFL context. It is an extended research to the earlier work of (Al-Shboul et al., 2013b).

\section{Literature Review}

\subsection{Rationale to Propose the Theoretical Framework}

Despite the availability of the popular scale to measure foreign language reading anxiety designed by Saito et al. (1999), the Foreign Language Reading Anxiety Scale (FLRAS) has not covered all potential sources of foreign language reading anxiety. Furthermore, the scale is typically used to reveal whether there is a distinction of foreign language anxiety in general and foreign language reading anxiety as a specific skill; therefore, there is a still need to offer a model that captures the possible sources of English language reading anxiety in particular. Even supposing there is a model somewhere which is anonymous for the researcher, the sources of foreign language reading anxiety vary according to the culture and the target language for the reason of the difference of the transcript of the mother tongue and the target language.

\subsection{Theoretical Framework of Potential Sources of Foreign Language Reading Anxiety}

Though little research has been conducted to investigate the sources of foreign language reading anxiety, there have been different causes resulting in different studies from different contexts. For example, in the early work of Saito et al. (1999), two main aspects that elicit foreign language reading anxiety were found: unfamiliar writing system and unfamiliar culture. However, congruent results in different contexts have not supported the aspect of unfamiliar writing systems (Kuru-Gonen, 2009; Liu, 2011; Miyanaga, 2007). The unfamiliar writing system aspect was found due to the comparison of foreign language reading anxiety in different target languages. In Saito et al. (1999) English university students who enrolled in French, Japanese, and Russian courses as a foreign language were studied to approve the discrimination of foreign language reading anxiety from foreign language anxiety. In their study, the comparison level of reading anxiety among the three target languages where English learners who were learning French refer to French as a cognate language in terms of the writing system whereas those who were learning Russian language refer to it as a semi-cognate language, and those who were learning Japanese language refer to Japanese as a non-cognate language. Thus, the unfamiliar writing system aspect was hypothesized as an aspect of foreign language reading anxiety among the three different writing system groups. In contrast, unfamiliar writing system aspect has not appeared in other studies in which only one language had been investigated 
(Kuru-Gonen, 2005, 2009; Liu, 2011; Miyanaga, 2007).

It seems that sources of foreign language reading anxiety have not been investigated thoroughly. Furthermore, Saito et al. (1999) has suggested that the sources of foreign language reading anxiety are still an open query. Consequently, the researcher postulates that foreign language reading anxiety is caused by personal factors and text features.

\subsection{Foreign Language Reading Anxiety Caused by Personal Factors}

It is theorized that there are two sub-factors under the concept of personal factors, which are;

1) Worry about Reading Effects

Reading in a foreign language and anxiety are joined in the same way that traditional conditioning works. Mainly, reading aloud is paired with anxious unconditioned stimulus, which brings a negative reaction (Jalongo \& Hirsh, 2010). For example, if a student is asked to read aloud, the act triggers the amygdale of the brain which produces instant worry and anxiety.

Students are anxious during and after reading in a foreign language. They are most often asked to read in front of their classmates. Consequently, students concentrate on performance rather than comprehension. If they were asked again to demonstrate the idea, in most cases they would lose what has been read. Alternately, if they were not sure whether they would be asked after reading, they might be more anxious during and after the reading task which creates a sense of anxiety that disturbs reading comprehension and performance at the same time.

Empirical studies have found that worrying about reading effect is a source of foreign language reading anxiety. For instance, in Zhao (2009) study, modified FLRAS was administered to 125 English university students who enrolled in a Chinese course to measure the level of foreign language reading anxiety among the Chinese learners in the United States. In FLRAS, there were two items that reflect worrying about reading effects; item (1) which states, "I get upset when I'm not sure I understand what I am reading in Chinese," and item (2) which states "when reading Chinese, I often understand the words but still can't quite understand what author is saying." In both items, approximately $42.8 \%$, and $33 \%$ of the participants respectively agreed or strongly agreed to indicate that worry about reading effect was identified as a source of foreign language reading anxiety in the study. Even though, the second item was misunderstood in the scale which basically reflects unfamiliar culture in which it was thought. It appears that the first item covers the large percentage compared to the second which confirms the claim of Zhao (2009) that worrying about reading effect could be a source of foreign language reading anxiety.

Huang (2001) distributed FLRAS to 236 Chinese university students who enrolled in an English course to measure the level of foreign language reading anxiety among the Chinese learners in Taiwan. Responses of the participants to the items were dissimilar to the previous studies. Approximately, $75 \%$ of the participants agreed or strongly agreed to item (1), and $63 \%$ agreed or strongly agreed to item (2). It supports that worry about reading effects as a source of foreign language reading anxiety in different target languages.

Apart from the quantitative studies, Kuru-Gonen $(2005,2009)$ conducted a qualitative study to find out that fear of comprehension is a reading anxiety caused by the personal factor. In her studies, $26 \%$ of the communication units of the analysis from the diaries indicated students' feeling about comprehension. Students are anxious of not understanding the foreign language text before and while reading.

\section{2) Afraid of Making Errors}

Language anxiety is complexly intertwined with self-confidence though the latter is characterized as a positive component (Brown, 2007; Gardner, Tremblay, \& Masgoret, 1997). Students who lack self-confidence are often afraid of participation in reading tasks in order to avoid making errors. Hence, this sense of feeling leads students to escalate the anxiety in foreign language reading. Therefore, by way of anxiety increase, their reading performance decreases, which ultimately shows an abnormality of their reading ability and unconstructive influences on language proficiency.

Research on foreign language anxiety has admitted the crucial role of lack of self-confidence in causing the state of fear of making errors. Nonetheless, the confused results that showed the lack of self-confidence and fear of making errors as one or two separated components, it seems that both connote the same sequential sense in the action of reading where any cursors to the other.

In Kuru-Gonen (2009); Miyanaga (2007), lack of self-confidence in reading was assigned as a source of foreign language reading anxiety. Alternatively, different studies in foreign language anxiety established afraid of making mistakes as a source of foreign language anxiety(Celebi, 2009; Cubukcu, 2007; Dalkilic, 2001; Hauck \& Hurd, 2005; M. Liu, 2007; Macintyre, 1995; Marwan, 2007, 2008; Merc, 2011; Ohata, 2005; Toth, 2011; William \& 
Andrade, 2008; Yan \& Horwitz, 2008). Nevertheless, it has been previously proven that foreign language reading anxiety is distinct phenomenon but related to foreign language anxiety (Kuru-Gonen, 2009; Saito et al., 1999; Sellers, 2000; $\mathrm{Wu}, 2011)$. That is there are some particular components shared between the two constructs.

\subsection{Foreign Language Reading Anxiety Caused by Text Features}

Also, it is theorized that there are three factors under the concept of the text features which are;

\section{1) Unfamiliar Culture}

Reading task is not only an interaction between the reader and the thoughts of the author, it is also incidentally interaction between the reader and the shared knowledge of the cultural history in the printed materials (In Tomasello, 1999; as cited in confirmed Miyamoto, \& Della-Chiesa, 2008). Experimental Research in the field has confirmed the role it plays in reading comprehension. Razi (2004) hypothesized that cultural familiarity had a significant impact on reading comprehension; to discover the effect of cultural schema on reading comprehension, 60 students in the English language teaching department who were learning English as a foreign language in a Turkish university were employed for the purpose of the study. With concern to the range of the grade point average, homogeneity, and a reliable reading text, results of a One-Way ANOVA test supported which hypothesis that readers are expected to achieve the author's anticipated meaning by linking existing knowledge with what they read.

Unfamiliar culture was found to be a source of foreign language reading anxiety. In the seminal work of Saito et al. (1999), it is also originated to be a great aspect to elicit anxiety in foreign language reading. Furthermore, Kuru-Gonen (2009) found that unknown cultural content blocks the students from understanding foreign language script.

\section{2) Unfamiliar Topic}

Topics which are not interesting or difficult for readers may lead to reading anxiety. Kuru-Gonen (2009) found uninteresting topics a source of foreign language reading anxiety caused by reading text. In her qualitative part of the study, she randomly investigated 25 students aiming to find the sources of foreign language reading anxiety. Utilizing a constant comparison method; the interviews and students' diaries were combined; findings showed that 210 communication units which connote $33 \%$ were categorized under the topic group. It was noticeable that topic cause ranked as the highest number of communication units and percentage as a source of foreign language reading anxiety in the study.

In Zhao (2009) Responses of the participants to the item (5) of FLRAS which stated, "I am nervous when I am reading a passage in Chinese when I am not familiar with the topic" was high. $44 \%$ of the participants agreed or strongly agreed with the item. In such way, unfamiliar topic was allocated as a source of reading anxiety in a foreign language.

\section{3) Unknown Vocabulary}

Unknown vocabulary has been found to be another source of foreign language reading anxiety. In Kuru-Gonen (2009), unknown vocabulary in reading a foreign language text appeared to be another source of anxiety. $20 \%$ of the communication units which related to text category fit to the students' statement of anxiety about new words through reading English language text.

In Al-Shboul et al. (2013a) study, the five sources have been captured in a single study. The theorized aspects were the most prominent causes that induce the sources of foreign language reading anxiety. It was generated from the ground study as an exploration stage. Thus, this current study in combined with the previous might contribute to existent literature as the most generalized and explained study.

\section{Methodology}

\subsection{The Setting and the Participants}

According to Horwitz et al. (1986) anxious students are common in foreign language classrooms, at least in the beginning classes at the university level. Therefore, the participants of this study were recruited from bachelor students during the second semester in the academic year 2011/2012 enrolled at Yarmouk University; it is a well-known public university in Jordan. According to the description of the university at the university's website (www.yu.edu.jo), the university has a language centre which is one of the largest centres in the university. Every semester the centre serves nearly six thousand students from various disciplines with the aim to improve the performance of students in the Basic English skills. The centre teaches three courses in the English language which are compulsory for the undergraduate level. Students may be exempted from one or two of them based on their scores in the placement test. All exams at the University for these Compulsory Courses are computerized to 
ensure rapid feedback and strict neutrality in the measurement of student performance and evaluation of their achievement. Table 1, present the total number and percentage of the population according to gender and faculty.

Table 1 . The distribution of the population according to gender and faculty

\begin{tabular}{|c|c|c|c|c|c|c|}
\hline \multirow[b]{2}{*}{ Faculty } & \multicolumn{6}{|l|}{ Population } \\
\hline & Population & Male & Female & $\begin{array}{l}\text { Total } \\
\text { Percentage }\end{array}$ & $\begin{array}{l}\text { Male } \\
\text { Percentage }\end{array}$ & $\begin{array}{l}\text { Female } \\
\text { Percentage }\end{array}$ \\
\hline Mass Communication & 205 & 95 & 110 & $3 \%$ & $1 \%$ & $2 \%$ \\
\hline Tourism and Hotel Management & 61 & 44 & 17 & $1 \%$ & $1 \%$ & $2 \%$ \\
\hline Law & 165 & 121 & 44 & $2 \%$ & $2 \%$ & $1 \%$ \\
\hline $\begin{array}{l}\text { Hijjawi for Engineering } \\
\text { Technology }\end{array}$ & 487 & 262 & 225 & $7 \%$ & $4 \%$ & $3 \%$ \\
\hline Archaeology And Anthropology & 592 & 149 & 443 & $9 \%$ & $2 \%$ & $7 \%$ \\
\hline $\begin{array}{l}\text { Economics and Administrative } \\
\text { Sciences }\end{array}$ & 823 & 638 & 185 & $12 \%$ & $10 \%$ & $3 \%$ \\
\hline Fine Arts & 404 & 184 & 220 & $6 \%$ & $3 \%$ & $3 \%$ \\
\hline Arts & 1045 & 362 & 683 & $16 \%$ & $5 \%$ & $10 \%$ \\
\hline Physical Education & 433 & 282 & 151 & $7 \%$ & $4 \%$ & $2 \%$ \\
\hline Education & 278 & 120 & 158 & $4 \%$ & $2 \%$ & $2 \%$ \\
\hline Information Technology & 832 & 114 & 718 & $13 \%$ & $2 \%$ & $11 \%$ \\
\hline Science & 636 & 258 & 378 & $10 \%$ & $4 \%$ & $6 \%$ \\
\hline Shari'a and Islamic Studies & 685 & 258 & 427 & $10 \%$ & $4 \%$ & $6 \%$ \\
\hline Total & 6646 & 2887 & 3759 & $100 \%$ & $43 \%$ & $57 \%$ \\
\hline
\end{tabular}

Source: Admission and Registration Department at Yarmouk University, letter 1936, Date 12 Feb., 2012.

\subsection{Sample Size}

The sample was large enough to guarantee the representation of the population of the study. Typically, quantitative studies utilize random sampling but due to the researcher's budget and other administrative constraints, quota sampling was taken. However, the paramount has been done to suit the selection of natural surroundings. The researcher surveyed the largest number realizable though a minimum of 384 participants is considered as an appropriate number to reflect the population of (6646) students within (-/+ 5\%) surrounded by $95 \%$ of confidence (Teddlie \& Tashakkori, 2009). To ensure that the number was over the strata, 1500 questionnaires were distributed carefully to the target population. The returned questionnaires which were untouched, neglected some items, or seemed unread carefully were all eliminated totally from the study. Thus, only 1006 questionnaires were valid for the purpose of the analysis.

To fulfill the requirement of the quota sampling selection, an equal portion from the target population was arbitrarily allocated. Table 2, represent the number of the nominated and selected sample according to gender and faculty.

Table 2. The number of the nominated and selected sample according to gender and faculty

\begin{tabular}{lllllll}
\hline \multicolumn{2}{l}{ Nominated Sample } & & \multicolumn{4}{l}{ Selected Sample } \\
\hline Total & Sample & Male & Female & Male & Female & Total \\
Sample & Percentage & Sample & Sample & Sample & Sample & \\
21 & $10 \%$ & 13 & 8 & 4 & 8 & 12 \\
18 & $30 \%$ & 6 & 12 & 4 & 8 & 12 \\
15 & $9 \%$ & 10 & 5 & 8 & 4 & 12 \\
146 & $30 \%$ & 60 & 86 & 16 & 12 & 28 \\
49 & $8 \%$ & 18 & 31 & 8 & 28 & 36 \\
148 & $18 \%$ & 63 & 85 & 40 & 12 & 52 \\
\hline
\end{tabular}




\begin{tabular}{lllllll}
\hline 55 & $14 \%$ & 28 & 27 & 12 & 12 & 24 \\
176 & $17 \%$ & 44 & 132 & 20 & 40 & 60 \\
41 & $9 \%$ & 25 & 16 & 16 & 8 & 24 \\
84 & $30 \%$ & 14 & 70 & 8 & 8 & 16 \\
59 & $7 \%$ & 13 & 46 & 8 & 44 & 52 \\
115 & $18 \%$ & 41 & 74 & 16 & 24 & 40 \\
79 & $12 \%$ & 26 & 53 & 16 & 24 & 40 \\
1006 & $212 \%$ & 361 & 645 & 176 & 232 & 408 \\
\hline
\end{tabular}

The valid questionnaires were quite enough to represent the characterization of the target population. The 400 number was identified, which is observed as the appropriate number to garb the smallest nominated sample portion. After the portion of each stratum was taken from the center of the postgraduate office at Yarmouk University, the researcher used an Excel sheet to calculate the percentage of each stratum by dividing the number of students for each faculty and the number of the total population. Also, for the gender specification, the same was done. The percentage number then multiplies by 400 and at the same time divided by 100 to know the number of sample that should be selected. Consequently, 408 were used as a rounded number in the final analysis as a representative sample number for the target population.

\subsection{The Instrumentation}

The developed instrument was based on the theoretical framework of the current study and the generated themes from the prior work of (Al-Shboul et al., 2013b). The obtained themes and specific statements that gathered from the informants in the previous study were used to create the instrument. The instrument was then used to measure the trend of the sources of foreign language reading anxiety among the students at Yarmouk University.

\subsubsection{Validity}

In the quantitative research, the term validity refers to the degree to which the instrument measures the concept it is supposed to be measured (Ary, Jacobs, Razavieh, \& Sorensen, 2010). There are different types of validity but in line with the previous work which demonstrated the analogue of validity when credibility was demonstrated (Al-Shboul et al., 2013b), it seems that the face and content validity were adequate to ensure that the instrument actually measures what is supposed to be measured. Accordingly, the instrument was given to a jury of two doctors from the education department, five teachers from the language center, and two PhD students in the field of foreign language teaching to review and comment on the layout and the statements. The instrument looked right, read right, and felt right, which reflected high-quality of face validity, and to reflect the content validity; many comments on the items were taken into consideration. Finally, 26 from initial 40 generated statements were mostly agreed on. According to the majority, redundant items were deleted while the ambiguity items were modified.

\subsubsection{Reliability}

In the quantitative research, the term reliability refers to the degree to which the instrument consistently measures whatever it is proposed to be measured (Ary et al., 2010). It is an essential in the quantitative research to examine the consistency of the students' responses to the different statements of items that assess the same domain of the developed instrument. Accordingly, Cronbach's alpha was used to measure the reliability coefficient which is the most common measure used to calculate the reliability.

After the comments and suggestions were taken from the jury members, the final version of the instrument was piloted on 30 respondents from the target population with taking in consideration that not be included again in the real study. The overall Cronbach's alpha was 0.846 . Though slight decrease was demonstrated in the real study to be 0.834 , which still indicates the acceptable value in the educational research (Ary et al., 2010). Table 3 , represents the reliability coefficient (Cronbach'salpha) for each aspect and the whole instrument. 
Table 3. Presentation of the reliability coefficient (cronbach'salpha)

\begin{tabular}{lll}
\hline Domain & Item & Reliability Coefficient \\
\hline Unknown Vocabulary & $1-6$ & 0.705 \\
Unfamiliar Topic & $7-10$ & Text Features \\
Unfamiliar Culture & $11-15$ & \\
Afraid of Making Errors & $16-20$ & 0.786 \\
Worry about Reading Effects & $21-26$ & Personal Factors \\
Overall & $1-26$ & 0.834 \\
\hline
\end{tabular}

\section{Results}

To examine the extent of the sources of foreign language reading anxiety at Yarmouk University, descriptive statistics were used to present the results. The results were interpreted in two forms; first, the full statements which reflect the instrument were exhibited to give an overview about the whole instrument. Second, each domain was represented to specify the percentage according to its category. The following tables 4 and 5 represent the frequencies and percentages of the instrument developed and the specific domains of the sources of English language reading anxiety (Al-Shboul et al., 2013b).

Table 4. The frequencies and percentages of the instrument

\begin{tabular}{|c|c|c|c|c|c|c|}
\hline o & nents & $\mathrm{SD}^{*}$ & $\mathrm{D}$ & $\mathrm{N}$ & A & SA \\
\hline & \multirow{2}{*}{$\begin{array}{l}\text { When I am reading in English, I get very upset and worry } \\
\text { whenever I encounter strange vocabulary. }\end{array}$} & 28 & 59 & 45 & 180 & 96 \\
\hline & & $7 \% *$ & $15 \%$ & $11 \%$ & $44 \%$ & $24 \%$ \\
\hline & \multirow{2}{*}{$\begin{array}{l}\text { I focus on words in reading English texts because if I know } \\
\text { the terms, I can understand the text. }\end{array}$} & 20 & 14 & 32 & 156 & 186 \\
\hline & & $5 \%$ & $3 \%$ & $8 \%$ & $38 \%$ & $46 \%$ \\
\hline & \multirow{2}{*}{$\begin{array}{l}\text { I feel anxious in reading English when I encounter series of } \\
\text { three strange words. }\end{array}$} & 15 & 52 & 59 & 156 & 126 \\
\hline & & $4^{0}$ & $13 \%$ & $15 \%$ & $38 \%$ & $31 \%$ \\
\hline & \multirow{2}{*}{ ext in English when I know its translation. } & 1 & 14 & 26 & 117 & 233 \\
\hline & & $4 \%$ & $3 \%$ & $6 \%$ & $29 \%$ & $57 \%$ \\
\hline & \multirow{2}{*}{$\begin{array}{l}\text { I do not like to read an English text that has lots of difficult } \\
\text { words. }\end{array}$} & 3 & 55 & 67 & 131 & 123 \\
\hline & & $8 \%$ & $14 \%$ & $16 \%$ & $32 \%$ & $30 \%$ \\
\hline & \multirow{2}{*}{$\begin{array}{l}\text { When I am reading in English, I feel upset and anxious if I } \\
\text { encounter words the meaning of which I do not know. }\end{array}$} & 3 & 86 & 79 & 126 & 79 \\
\hline & & 10 & $21 \%$ & $19 \%$ & $31 \%$ & $19 \%$ \\
\hline & \multirow{2}{*}{$\begin{array}{l}\text { I enjoy English reading when I understand at least some } \\
\text { portion of the text. }\end{array}$} & 23 & 37 & 65 & 173 & 110 \\
\hline & & $6^{0}$ & $9 \%$ & $16 \%$ & $42 \%$ & $27 \%$ \\
\hline & \multirow{2}{*}{$\begin{array}{l}\text { I do not prefer reading unfamiliar topics, particularly in the } \\
\text { English language. }\end{array}$} & 4 & 57 & 84 & 91 & 133 \\
\hline & & $11^{\circ}$ & $14 \%$ & $21 \%$ & $22 \%$ & $33 \%$ \\
\hline & \multirow{2}{*}{$\begin{array}{l}\text { The most things I like to read in English are short stories } \\
\text { because they have easy words, and their topics are common. }\end{array}$} & 2 & 43 & 81 & 164 & 92 \\
\hline & & $7 \%$ & $11 \%$ & $20 \%$ & $40 \%$ & $23 \%$ \\
\hline \multirow{2}{*}{10} & \multirow{2}{*}{$\begin{array}{l}\text { I feel anxious when I am reading a topic in the English } \\
\text { language which I have no idea about. }\end{array}$} & 2 & 10 & 87 & 126 & 66 \\
\hline & & $5 \%$ & $27 \%$ & $21 \%$ & $31 \%$ & $16 \%$ \\
\hline \multirow{2}{*}{11} & \multirow{2}{*}{$\begin{array}{l}\text { In reading English, I hardly understand the idea if there is } \\
\text { more than one meaning for each word. }\end{array}$} & 3 & 82 & 95 & 127 & 74 \\
\hline & & 70 & $20 \%$ & $23 \%$ & $31 \%$ & $18 \%$ \\
\hline \multirow{2}{*}{12} & \multirow{2}{*}{$\begin{array}{l}\text { When I read English, I often understand the words, but I still } \\
\text { cannot quite understand what the writer says. }\end{array}$} & 2 & 91 & 10 & 111 & 78 \\
\hline & & $6 \%$ & $22 \%$ & $25 \%$ & $27 \%$ & $19 \%$ \\
\hline \multirow[t]{2}{*}{13} & \multirow{2}{*}{ I usually translate word by word when I am reading English. } & 68 & 126 & 77 & 93 & 44 \\
\hline & & $17 \%$ & $31 \%$ & $19 \%$ & $23 \%$ & $11 \%$ \\
\hline \multirow{2}{*}{14} & \multirow{2}{*}{$\begin{array}{l}\text { It is frustrating in reading English when one word is } \\
\text { connected with another to change the meaning. }\end{array}$} & 28 & 87 & 121 & 116 & 56 \\
\hline & & $7 \%$ & $21 \%$ & $30 \%$ & $28 \%$ & $14 \%$ \\
\hline 5 & I most often feel that I cannot understand an English text even & 64 & 100 & 90 & 103 & 51 \\
\hline
\end{tabular}


though I know every word's meaning.

16 and easy word wrongly. class. pronounced.

I prefer silent reading rather than reading aloud. than focusing on understanding the text. though it is easy. accent rather than understanding. reading in English or not.

I feel anxious in reading aloud in fear of making errors.

\begin{tabular}{|c|c|c|c|c|}
\hline $16 \%$ & $25 \%$ & $22 \%$ & $25 \%$ & $13 \%$ \\
\hline 49 & 64 & 56 & 114 & 125 \\
\hline $12 \%$ & $16 \%$ & $14 \%$ & $28 \%$ & $31 \%$ \\
\hline 39 & 62 & 52 & 126 & 129 \\
\hline $10 \%$ & $15 \%$ & $13 \%$ & $31 \%$ & $32 \%$ \\
\hline 16 & 35 & 56 & 138 & 163 \\
\hline $4 \%$ & $9 \%$ & $14 \%$ & $34 \%$ & $40 \%$ \\
\hline 16 & 41 & 71 & 173 & 107 \\
\hline $4 \%$ & $10 \%$ & $17 \%$ & $42 \%$ & $26 \%$ \\
\hline 48 & 55 & 78 & 101 & 126 \\
\hline $12 \%$ & $14 \%$ & $19 \%$ & $25 \%$ & $31 \%$ \\
\hline 16 & 44 & 71 & 141 & 136 \\
\hline $4 \%$ & $11 \%$ & $17 \%$ & $35 \%$ & $33 \%$ \\
\hline 32 & 70 & 100 & 146 & 60 \\
\hline $8 \%$ & $17 \%$ & $25 \%$ & $36 \%$ & $15 \%$ \\
\hline 29 & 57 & 68 & 146 & 108 \\
\hline $7 \%$ & $14 \%$ & $17 \%$ & $36 \%$ & $27 \%$ \\
\hline 19 & 60 & 73 & 143 & 113 \\
\hline $5 \%$ & $15 \%$ & $18 \%$ & $35 \%$ & $28 \%$ \\
\hline 17 & 39 & 104 & 161 & 87 \\
\hline $4 \%$ & $10 \%$ & $26 \%$ & $40 \%$ & $21 \%$ \\
\hline 68 & 82 & 78 & 108 & 72 \\
\hline $17 \%$ & $20 \%$ & $19 \%$ & $27 \%$ & $18 \%$ \\
\hline
\end{tabular}

I feel embarrassed in front of others if I pronounce a simple

I prefer to prepare too much and search for the phonetic transcript prior to the class if I was expected to read in the

I feel irritated if I encounter a word I do not know how it is

When I am reading aloud, I focus on reading correctly rather

In reading aloud in the class, I do not understand the text even

I enjoy silent reading because I can easily understand the text.

When reading English aloud in the class I focus on word

I get upset when I am not sure whether I understand what I am

When reading English, I get disturbed and do not remember what I have read.

$17 \% \quad 20 \% \quad 19 \% \quad 27 \%$

*SD = strongly disagree; $\mathrm{D}=$ disagree; $\mathrm{N}=$ neither disagree nor agree; $\mathrm{A}=$ agree; $\mathrm{SA}=$ strongly agree.

**The data in this table are rounded to the nearest whole percentages. Therefore digits may not equate to 100 due to rounding.

The statements presented were insightful of unknown vocabulary, unfamiliar topic, unfamiliar culture, afraid of making errors, and worry about reading effects. All answers and percentages that referred to the number of respondents who agreed or strongly agreed to the developed instrument were reported in the table.

According to table 4, $68 \%$ of the respondents agree (44\% agree; $24 \%$ strongly agree); $22 \%$ do not agree (15\% disagree; $7 \%$ strongly disagree), and $11 \%$ neither agree nor disagree with the statement "When I am reading in English, I get very upset and worry whenever I encounter strange vocabulary." From these responses, one can conclude that unknown vocabulary creates anxiety towards reading in the English language which ultimately lessens the students' importance of English reading materials that comprise contemporary knowledge.

$84 \%$ of the respondents agree (38\% agree; $46 \%$ strongly agree); $8 \%$ do not agree (3\% disagree; $5 \%$ strongly disagree), and $8 \%$ neither agreed nor disagree with the statement "I focus on words in reading English texts because if I know the terms, I can understand the text." From these responses, it can be understood that students refer to vocabulary in reading as an important sub-skill they must acquire to avoid reading anxiety in the English language.

$69 \%$ of the respondents agree (38\% agree; $31 \%$ strongly agree); $17 \%$ do not agree (13\% disagree; $4 \%$ strongly disagree), and 15\% neither agreed nor disagree with the statement "I feel anxious in reading English when I encounter series of three strange words." It can also be acknowledged that not only not knowing a word causes anxiety in reading English but also the unknown surrounding words make the act of reading more anxious and challenging.

$86 \%$ of the respondents agree (29\% agree; $57 \%$ strongly agree); $7 \%$ do not agree (3\% disagree; $4 \%$ strongly disagree), and 6\% neither agreed nor disagree with the statement "I enjoy reading a text in English when I know its translation." From these responses, one can deduce that reading can be an enjoyable task if all vocabulary were comprehended. 
$62 \%$ of the respondents agree ( $32 \%$ agree; $30 \%$ strongly agree); $22 \%$ do not agree (14\% disagree; $8 \%$ strongly disagree), and $16 \%$ neither agreed nor disagree with the statement "I do not like to read an English text that has lots of difficult words." Clearly, lack of vocabulary causes reading anxiety in a foreign language.

$50 \%$ of the respondents agree (31\% agree; $19 \%$ strongly agree); $31 \%$ do not agree $(21 \%$ disagree; $10 \%$ strongly disagree), and 19\% neither agreed nor disagree with the statement "When I am reading in English, I feel upset and anxious if I encounter words the meaning of which I do not know." From these responses, one can conclude that also difficult words in English texts cause reading anxiety.

$69 \%$ of the respondents agree ( $42 \%$ agree; $27 \%$ strongly agree); $15 \%$ do not agree (9\% disagree; $6 \%$ strongly disagree), and 16\% neither agreed nor disagree with the statement "I enjoy English reading when I understand at least some portion of the text." From these responses, one can recognize that familiar topics are enjoyable in English reading.

$55 \%$ of the respondents agree ( $22 \%$ agree; $33 \%$ strongly agree); $25 \%$ do not agree ( $14 \%$ disagree; $11 \%$ strongly disagree), and $21 \%$ neither agreed nor disagree with the statement "I do not prefer reading unfamiliar topics, particularly in the English language." It is clear that previous knowledge about the topic can predominantly ease reading in a foreign language.

$63 \%$ of the respondents agree ( $40 \%$ agree; $23 \%$ strongly agree); $18 \%$ do not agree (11\% disagree; $7 \%$ strongly disagree), and $20 \%$ neither agreed nor disagree with the statement "The most things I like to read in English are short stories because they have easy words, and their topics are common." Results show that short stories are the preferred reading material in the English language for the students due to the familiarity of their conventional manner.

$47 \%$ of the respondents agree (31\% agree; $16 \%$ strongly agree); $32 \%$ do not agree ( $27 \%$ disagree; $5 \%$ strongly disagree), and $21 \%$ neither agreed nor disagree with the statement "I feel anxious when I am reading a topic in the English language which I have no idea about." It can be concluded that alien topics induce reading anxiety in the English language.

$49 \%$ of the respondents agree (31\% agree; $18 \%$ strongly agree); $27 \%$ do not agree ( $20 \%$ disagree; $7 \%$ strongly disagree), and 23\% neither agreed nor disagree with the statement "In reading English, I hardly understand the idea if there is more than one meaning for each word." From these responses, one can understand that due to the variety of meaning for each English word in the target language, one must be familiar with the cultural text to connote the meaning accurately.

$46 \%$ of the respondents agree ( $27 \%$ agree; $19 \%$ strongly agree); $28 \%$ do not agree ( $22 \%$ disagree; $6 \%$ strongly disagree), and $25 \%$ neither agreed nor disagree with the statement "When I read English, I often understand the words, but I still cannot quite understand what the writer says." The answers show that knowing the words does not necessarily lead to understand the text as a whole unit although the student's greater concerns are the words.

$34 \%$ of the respondents agree ( $23 \%$ agree; $11 \%$ strongly agree); $48 \%$ do not agree (31\% disagree; $17 \%$ strongly disagree), and $19 \%$ neither agreed nor disagree with the statement "I usually translate word by word when I am reading English." This confirms that regardless of knowing all vocabulary in the text, comprehension is often not achieved.

$42 \%$ of the respondents agree ( $28 \%$ agree; $14 \%$ strongly agree); $28 \%$ do not agree ( $21 \%$ disagree; $7 \%$ strongly disagree), and 30\% neither agreed nor disagree with the statement "It is frustrating in reading English when one word is connected with another to change the meaning." It is clear that connected words may change the meaning, and this provokes more obscurity in reading English. To decrease this worry and obscurity, one must understand the cultural aspect.

$38 \%$ of the respondents agree ( $25 \%$ agree; $13 \%$ strongly agree); $41 \%$ do not agree ( $25 \%$ disagree; $16 \%$ strongly disagree), and $22 \%$ neither agreed nor disagree with the statement "I most often feel that I cannot understand an English text even though I know every word's meaning." From these responses, one may understand that most often meaning is not necessarily achieved by knowing everyone expression.

$59 \%$ of the respondents agree ( $28 \%$ agree; $31 \%$ strongly agree); $28 \%$ do not agree (16\% disagree; $12 \%$ strongly disagree), and $14 \%$ neither agreed nor disagree with the statement "I feel anxious in reading aloud in fear of making errors." The results show that students prefer not to read aloud in order to avoid making errors.

$63 \%$ of the respondents agree (31\% agree; $32 \%$ strongly agree); $25 \%$ do not agree ( $15 \%$ disagree; $10 \%$ strongly disagree), and $13 \%$ neither agreed nor disagree with the statement "I feel embarrassed in front of others if I 
pronounce a simple and easy word wrongly." Clearly, students have apprehension about reading any word imperfectly.

$74 \%$ of the respondents agree (34\% agree; $40 \%$ strongly agree); $13 \%$ do not agree (9\% disagree; $4 \%$ strongly disagree), and $14 \%$ neither agreed nor disagree with the statement "I prefer to prepare too much and search for the phonetic transcript prior to the class if I was expected to read in the class." From these responses, one can conclude that students worry more about pronunciation in reading. They are afraid of making even small inaccuracies.

$68 \%$ of the respondents agree (42\% agree; $26 \%$ strongly agree); $14 \%$ do not agree (10\% disagree; $4 \%$ strongly disagree), and 17\% neither agreed nor disagree with the statement "I feel irritated if I encounter a word I do not know how it is pronounced." It is understood that students are anxious about misreading any English term. It is an anxious situation in reading the foreign language aloud.

$56 \%$ of the respondents agree (25\% agree; $31 \%$ strongly agree); $26 \%$ do not agree (14\% disagree; $12 \%$ strongly disagree), and 19\% neither agreed nor disagree with the statement "I prefer silent reading rather than reading aloud." It can be concluded that students hate the task of reading aloud due to committing noticeable faults.

$68 \%$ of the respondents agree (35\% agree; $33 \%$ strongly agree); $15 \%$ do not agree (11\% disagree; $4 \%$ strongly disagree), and 17\% neither agreed nor disagree with the statement "When I am reading aloud, I focus on reading correctly rather than focus on understanding the text." From these responses, one can realize that students are worried about reading effects. Consequently, they focus on the act of reading rather than understanding in case of reading aloud.

$51 \%$ of the respondents agree (36\% agree; $15 \%$ strongly agree); $25 \%$ do not agree (17\% disagree; $8 \%$ strongly disagree), and $25 \%$ neither agreed nor disagree with the statement "In reading aloud in the class, I do not understand the text even though it is easy." It confirms that students are more concerned about performance. They pay more concentration on showing high-quality production, which reduces their understanding even if the text is unproblematic.

$63 \%$ of the respondents agree (36\% agree; $27 \%$ strongly agree); $21 \%$ do not agree (14\% disagree; $7 \%$ strongly disagree), and $17 \%$ neither agreed nor disagree with the statement "I enjoy silent reading because I can easily understand the text." It is clear that silent reading reduces worrying about the reading effects. Thus, it is desired for the students.

$63 \%$ of the respondents agree (35\% agree; $28 \%$ strongly agree); $20 \%$ do not agree (15\% disagree; $5 \%$ strongly disagree), and $18 \%$ neither agreed nor disagree with the statement "When reading English aloud in the class I focus on word accent rather than understanding." To keep away from being anxious about reading effects, clearly students focus on performance rather than understanding.

$61 \%$ of the respondents agree (40\% agree; $21 \%$ strongly agree); $14 \%$ do not agree (10\% disagree; $4 \%$ strongly disagree), and $26 \%$ neither agreed nor disagree with the statement "I get upset when I am not sure whether I understand what I am reading in English or not." The results show that students are not sure what they read due to worrying about reading effects.

$45 \%$ of the respondents agree (27\% agree; $18 \%$ strongly agree); $37 \%$ do not agree (20\% disagree; $17 \%$ strongly disagree), and 19\% neither agreed nor disagree with the statement "When reading English, I get disturbed and do not remember what I have read." It can be said that worrying about reading effects disturbs students and causes them to pay less focus.

Table 5. The percentages of the specific domains of the sources of foreign language reading anxiety

\begin{tabular}{llllllll}
\hline Range & Domain & SD & D & N & A & SA & Aspects \\
\hline $1-6$ & Unknown Vocabulary & $6 \%$ & $11 \%$ & $13 \% *$ & $35 \%$ & $35 \%$ & \\
$7-10$ & Unfamiliar Topic & $7 \%$ & $15 \%$ & $19 \%$ & $34 \%$ & $25 \%$ & Text Features \\
$11-15$ & Unfamiliar Culture & $10 \%$ & $24 \%$ & $24 \%$ & $27 \%$ & $15 \%$ & \\
$16-20$ & Afraid of Making Errors & $8 \%$ & $13 \%$ & $15 \%$ & $32 \%$ & $32 \%$ & \\
$21-26$ & Worry about Reading Effects & $7 \%$ & $14 \%$ & $20 \%$ & $35 \%$ & $24 \%$ & Personal Factors \\
\hline
\end{tabular}

*Data in the table are rounded according to the highest fraction to fix the total 100 percentage. 
To specify the percentage for each domain, arithmetic results were calculated. According to Table $5,70 \%$ of the respondents agree (35\% agree; $35 \%$ strongly agree); $17 \%$ do not agree (11\% disagree; $6 \%$ strongly disagree), and $13 \%$ neither agreed nor disagree with the generated theme named unknown vocabulary. From these responses, one can conclude that unknown vocabulary was ranked as the most frequent source of anxiety under the aspect of text features in reading English as a foreign language at Yarmouk University.

$59 \%$ of the respondents agree (34\% agree; $25 \%$ strongly agree); $22 \%$ do not agree ( $15 \%$ disagree; $7 \%$ strongly disagree), and $19 \%$ neither agreed nor disagree with the generated theme characterized as an unfamiliar topic. From the respondents' responses, one can conclude that the unfamiliar topic theme was ranked as the second most frequent source of anxiety under the aspect of text features in reading English as a foreign language at Yarmouk University.

$42 \%$ of the respondents agree ( $27 \%$ agree; $15 \%$ strongly agree); $34 \%$ do not agree ( $24 \%$ disagree; $10 \%$ strongly disagree), and $24 \%$ neither agreed nor disagree with the generated theme named unfamiliar culture. From these responses, one can conclude that unfamiliar culture theme was ranked as the least frequently source of anxiety under the aspect of text features in reading English as a foreign language at Yarmouk University.

On the other hand, $64 \%$ of the respondents agree (32\% agree; $32 \%$ strongly agree); $21 \%$ do not agree (13\% disagree; $8 \%$ strongly disagree), and $15 \%$ neither agreed nor disagree with the generated theme named afraid of making errors. From these responses, one can conclude that afraid of making error theme was ranked as the most frequently source of anxiety under the aspect of a personal factor in reading English as a foreign language at Yarmouk University.

$59 \%$ of the respondents agree (35\% agree; $24 \%$ strongly agree); $21 \%$ do not agree ( $14 \%$ disagree; $7 \%$ strongly disagree), and $20 \%$ neither agreed nor disagree with the generated theme named worrying about reading effects. It can be concluded that worry about reading effects was ranked as the following frequently source of anxiety under the aspect of the personal factors in reading English as a foreign language at Yarmouk University.

Wide-ranging results show that $57 \%$ of the respondents agree (32\% agree; $25 \%$ strongly agree); $24 \%$ do not agree (17\% disagree; $7 \%$ strongly disagree), and $19 \%$ neither agreed nor disagree with the personal factor, yet $62 \%$ of the respondents agree (34\% agree; $28 \%$ strongly agree); $21 \%$ do not agree ( $14 \%$ disagree; $7 \%$ strongly disagree), and $17 \%$ neither agreed nor disagree with the text feature as a source of reading anxiety in English as a foreign language at Yarmouk University.

\section{Discussion}

Data gathered in the introspective stage from the previous work (Al-Shboul et al., 2013b) represented the emergent themes in the retrospective stage of the current work. The order of the sources of English language reading anxiety is identical in both studies according to text features and personal factors. Table 6 , represents the parallel concurrence percentage of themes in both studies.

Table 6. The parallel concurrence percentages of themes in both phases

\begin{tabular}{|c|c|c|c|c|c|}
\hline \multirow[b]{2}{*}{ Themes } & \multirow{2}{*}{$\begin{array}{l}\text { Previous Work } \\
\text { Percentage } \\
\text { Agreement }\end{array}$} & \multicolumn{2}{|c|}{ Current Work } & \multirow[b]{2}{*}{ Rank } & \multirow[b]{2}{*}{ Aspect } \\
\hline & & $\mathrm{N}^{*}$ & A \& SA & & \\
\hline Unknown Vocabulary** & $100 \%$ & $13 \%$ & $70 \%$ & 1 & \multirow{3}{*}{ Text Feature } \\
\hline Unfamiliar Topic & $100 \%$ & $19 \%$ & $59 \%$ & 2 & \\
\hline Unfamiliar Culture & $67 \%$ & $24 \%$ & $42 \%$ & 3 & \\
\hline $\begin{array}{l}\text { Afraid of Making } \\
\text { Errors }\end{array}$ & $100 \%$ & $15 \%$ & $64 \%$ & 1 & \multirow{2}{*}{$\begin{array}{l}\text { Personal } \\
\text { Factor }\end{array}$} \\
\hline $\begin{array}{l}\text { Worry about Reading } \\
\text { Effects }\end{array}$ & $67 \%$ & $20 \%$ & $59 \%$ & 2 & \\
\hline
\end{tabular}

$* \mathrm{~N}=$ neither disagree nor agree; $\mathrm{A} \& \mathrm{SA}=$ agree and strongly agree.

** Unknown vocabulary theme ranked as the first in comparison with the unfamiliar topic theme due to the large number of excerpts.

Regardless of the small percentage of agreement on the unfamiliar culture theme in the current study due to the high percentage on the nonaligned answer which might be a consequence of more or less disclosure to reading 
cultural texts, in particular. Plainly, the representative sample from the current study agrees on the five themes that emerged from the previous field work. The following represents the corresponding emergent themes in both studies.

\subsection{Unknown Vocabulary}

Twenty four excerpts from the informants' interviews and diaries were gathered in the previous work. However, only 14 of the most prominent or repetitive excerpts facilitated to generate the six statements that characterize the current theme. Table 7 presents the connection of the collective data of the unknown vocabulary theme.

Table 7. The connection of the collective data of the unknown vocabulary theme

\begin{tabular}{lllll}
\hline Previous Study & & & Current Study & \\
Informant No. & Type of Document & Excerpt Range & Statement No. & Agreement \\
\hline 5 & Interview & $919-1044$ & 1 & $68 \%$ \\
2 & Diary & $114-191$ & & \\
5 & Interview & $5110-5180$ & 2 & $84 \%$ \\
6 & Interview & $4949-5068$ & & \\
4 & Interview & $6135-6374$ & & $69 \%$ \\
3 & Interview & $885-493$ & 3 & \\
6 & Diary & $1615-1794$ & & \\
5 & Interview & $1763-1870$ & & \\
6 & Diary & $741-872$ & 4 & $66 \%$ \\
4 & Diary & $4059-4604$ & & \\
2 & Diary & $30-109$ & 5 & $50 \%$ \\
4 & Diary & $4059-4604$ & 5 & \\
1 & Diary & $849-918$ & 6 & \\
3 & Interview & $2943-3143$ & & \\
\hline
\end{tabular}

According to Table 7, the first statement in the instrument corresponded to the fifth interview and the second diary of the informants who were anxious about reading because of word difficulty. $68 \%$ of the respondents agree or strongly agree with the statement which confirms that unknown vocabulary in English text lessens the curiosity in reading and creates an anxiety provoking situation.

The second statement was closely related to the fifth and sixth interview of the informants who focused on vocabulary. They believe that mastering the vocabulary means totally understanding the English text. $84 \%$ of the respondents agree or strongly agree with the statement. According to the large percentage, it is clear that students refer to vocabulary as an important sub-skill in reading.

The third statement was equivalent to the third and fourth interview and the sixth diary of the informants who were not only anxious about reading because of word complexity but also about the number of words in series of density, which create a more anxiety-provoking situation. $69 \%$ of the respondents agree or strongly agree with the statement which assures that not only some new vocabulary causes anxiety but also obscurities around the new words makes the task of reading more challenging.

The fourth statement was corresponding to the fifth interview and the fourth and sixth diary of the informants who were worried about unknowing the connote meaning of the English text in their mother tongue language. $86 \%$ of the respondents agree or strongly agree with the statement, which represents the highest percentage that reflects that reading might be an enjoyable task if all words were completely comprehended.

The fifth statement was parallel to the second and fourth diary of the informants who were concerned about reading an English text that involved lots of new words. $62 \%$ of the respondents agree or strongly agree on the statement which validates that dearth of vocabulary causes reading anxiety in the English language.

The sixth statement was analogous to the first diary and the third interview of the informants who were concerned of knowing every single word's meaning. $50 \%$ of the respondents agree or strongly agree on the statement which represented half of the representative sample, and this concludes that difficult words in English text cause reading anxiety. 
All informants participated in generating statements, which represent the premise from different points of views, and that assisted in obtaining the largest percentage of the respondents' agreements on the unknown vocabulary theme. $70 \% \%$ of the respondents agree or strongly agree on the theme which ranks it in the first position as a source of English language reading anxiety characterized by text features.

Congruent with this finding, unknown vocabulary was categorized to be one of five themes of anxiety caused by reading texts in the study of Turkish students who were learning English language as a foreign language (Kuru-Gonen, 2009).

Furthermore, in M.Liu (2007) study, lack of vocabulary was identified to be a main cause for Chinese students who were learning the English language. Participants revealed their worry of the speaking skill due to scarcity of vocabulary. Although the latter study was closer to foreign language anxiety in general, it also can be a shared component between foreign language anxiety in general and foreign language reading anxiety as a specific skill ever since foreign language reading anxiety was established to be a phenomenon related to but distinct from foreign language anxiety in general (Kuru-Gonen, 2005, 2007, 2009; Saito et al., 1999; Sellers, 2000; Wu, 2011). In the same way, in Walker (1997) thesis, interview data showed that highly anxious Chinese learners who learn English as a foreign language had fewer opportunities to succeed because of the insufficient vocabulary in the target language.

\subsection{Unfamiliar Topic}

Fifteen excerpts from the informants' interviews and diaries were gathered in the previous work. However, only 10 of the most prominent or repetitive excerpts facilitated to generate the four statements that characterize the current theme. Table 8 presents the connection of the collective data of the unfamiliar topic theme.

Table 8. The connection of the collective data of the unfamiliar topic theme

\begin{tabular}{lllll}
\hline $\begin{array}{l}\text { Previous Study } \\
\text { Informant No. }\end{array}$ & Type of Document & Excerpt Range & $\begin{array}{l}\text { Current Study } \\
\text { Statement No. }\end{array}$ & Agreement \\
\hline 1 & Interview & $519-821$ & & \\
5 & Interview & $3064-3312$ & 7 & $69 \%$ \\
5 & Interview & $5335-5510$ & & \\
1 & Interview & $6024-6061$ & & $55 \%$ \\
3 & Interview & $2819-2899$ & 8 & \\
4 & Diary & $2337-2467$ & & $63 \%$ \\
2 & Interview & $2872-2919$ & & \\
6 & Diary & $987-1183$ & 9 & $47 \%$ \\
4 & Interview & $4168-4398$ & & \\
4 & Interview & $8144-8287$ & 10 & \\
4 & Interview & $6416-6509$ & & \\
\hline
\end{tabular}

According to Table 8, the seventh statement was a consequent of the first and fifth interview of the informants who like and enjoy reading common topics or topics, which are narrowly related to their majors. In both cases, they understand much of the text, which results in finding pleasure in reading; otherwise, they quit reading because of anxiety in abnormal topics. $69 \%$ of the respondents agree or strongly agree on the statement which validates the reflection that the more familiar topic is the less anxiety provoking.

The eighth statement was closely related to the first and third interview and the fourth diary of the informants who are not used to read a variety of topics. $55 \%$ of the respondents agree or strongly agree with the statement which supports that previous knowledge about topics can ease reading in a foreign language.

The ninth statement was comparable to the second and fourth interview and the sixth diary of the informants who enjoy reading short stories due to the common style they carry. It is known that most short stories have the same expected ending which helps readers to understand. $63 \%$ of the respondents agree or strongly agree with the statement which tells that short stories are the preferred reading material in the English language among the students certifying that familiarity, and the ordinary manner of these topics are the grounds of preference.

The tenth statement was consequent to the fourth informants' interview taken on different occasions and observed by others through conducting the interviews which ensure that reading an abstract or having an analysis 
about the topic may create less anxious reading situation. $47 \%$ of the respondents agree or strongly agree on the statement which sustains that unfamiliar topics induce reading anxiety in the English language.

All informants participated in generating statements, which describe the unfamiliar topic theme from different points of views, and that assisted in obtaining the second largest percentage of respondents' agreements on the theme. $59 \%$ of the respondents agree or strongly agree with the theme which ranks it in the second position as a source of English language reading anxiety characterized by text feature.

A similar finding was found in Kuru-Gonen Kuru-Gonen (2009) study. However, the uninteresting topic theme occupied the largest portion of the Turkish students' diary and interviews as a source of foreign language reading anxiety.

In a different context, Zhao (2009) found an unfamiliar topic as a source of foreign language reading anxiety. The researcher utilized FLRAS to explore the foreign language reading anxiety level among 125 English students who were learning the Chinese language in the United States. Besides that, he used item (5) that stated, "I am nervous when I am reading a passage in Chinese when I am not familiar with the topic." $44 \%$ of the students agree or strongly agree with the implicit item that reveals that unfamiliar topic is one of the anxiety provoking sources in reading Chinese as a foreign language.

Considering that foreign language reading anxiety was found as a phenomenon related to but distinguished from foreign language anxiety in general, Lin (2009) found assigned writing subjects, which are not exciting to the learners to write about or not commonly related to daily life are a source of anxiety in the writing skill.

\subsection{Unfamiliar Culture}

Eleven excerpts from the informants' interviews and diaries were gathered in the previous work though 14 of the most prominent or repetitive excerpts facilitated to generate the five statements that characterize the current theme. Table 9 presents the connection of the collective data of the unfamiliar culture theme.

Table 9. The connection of the collective data of the unfamiliar culture theme

\begin{tabular}{lllll}
\hline $\begin{array}{l}\text { Previous Study } \\
\text { Informant No. }\end{array}$ & Type of Document & Excerpt Range & $\begin{array}{l}\text { Current Study } \\
\text { Statement No. }\end{array}$ & Agreement \\
\hline 1 & Diary & $849-963$ & & \\
2 & Interview & $3583-3888$ & 11 & $49 \%$ \\
2 & Interview & $5302-5413$ & & \\
3 & Interview & $1623-1707$ & & $46 \%$ \\
3 & Interview & $4020-4117$ & 12 & \\
4 & Interview & $3615-3761$ & & $34 \%$ \\
2 & Diary & $452-615$ & 13 & $42 \%$ \\
1 & Interview & $4750-4963$ & 14 & \\
2 & Diary & $452-615$ & & $38 \%$ \\
1 & Interview & $4750-4963$ & 15 & \\
3 & Interview & $1623-1707$ & & \\
3 & Interview & $4020-4117$ & & \\
\hline
\end{tabular}

According to Table 9, the eleventh statement was in correspondence to the second interview and the first diary of the informants who find difficulties in deducing the precise meaning of a word due to unfamiliar culture. Mostly, students are anxious if they know the meaning of the words in the text but cannot comprehend the overall meaning. $49 \%$ of the respondents agree or strongly agree with the statement which extends the understanding that the variety of possible Arabic meanings for each word in English creates anxiety provoked in the act of reading due to less awareness of the cultural aspect.

The twelfth statement was directly connected to the third and fourth interview of the informants who are apprehensive and stressful when knowing all individual words yet coming across complexity in assuming the author's meaning. $46 \%$ of the respondents agree or strongly agree with the statement which continues the belief of the students that knowing the words does not necessarily lead to comprehend the text as a whole piece in spite of the reality that the students' concern more about the vocabulary. 
The thirteenth statement was the same as the second diary of the informant who was not realizing that he ends up translating English texts when it comes as an unfamiliar culture, looking to the precise meaning which can fit the context. 34\% of the respondents agree or strongly agree with the statement which represents the smaller amount of percentage. It seems that the statement might be ambiguous for the majority or reflects in any case that in spite of knowing all vocabulary in the text, comprehension is often not achieved.

The fourteenth statement was alike the first interview of the informant who is more concerned of changing the meaning if one word joins with the other. It is a more nervous condition than the previous are. $42 \%$ of the respondents agree or strongly agree with the statement which holds that the understanding of the connection words in changing the meaning will create more anxiety if some of the cultural aspects were vague.

The fifteenth statement was parallel to the first and third interview and the second diary of the informants who often recognize the words' meaning independently in the text. However, they most often feel concerned about absorbing the whole text. $38 \%$ of the respondents agree or strongly agree on the statement which displays that most often meaning is not requisitely achieved by knowing every individual term.

One-third of the informants participated in generating statements, which represent the current theme from different points of view and that assisted in obtaining the reasonable amount of percentage of the respondents' agreements on the theme. It seems logical that the rest of the informants who were categorized as a low-level-of-proficiency did not contribute to this theme due to their lack experience in reading cultural texts, which are considered as the most difficult reading texts. Moreover, the less-percentage-of-agreement respondent who was affected by the uncertain answer was another declaration to the claim. $42 \%$ of the respondents agree or strongly agree on the theme which ranks it in the last position as a source of English language reading anxiety characterized by text features.

This finding related to the first study of foreign language reading anxiety. In Saito et al. (1999), unfamiliar cultural material was hypothesized to be an aspect that elicits foreign language reading anxiety. According to them, readers connect words to process the meaning of text. However, at some point the reader does not compose a logical massage which creates an anxious situation. This is because of the deficient awareness of the cultural material underlying the text.

In addition to that, Tanveer (2007) found that cultural differences between the foreign language learners, and the target language is a vital source of anxiety. In the study, a range of students, teachers, and practitioners from different nationalities who refer to English as a foreign/second language were investigated to declare that the more unfamiliar the culture is in the target language, the more it is possible to be an anxiety provoking situation.

\subsection{Afraid of Making Errors}

Even though eight excerpts from the informants' interviews and diaries were gathered in the previous work, 23 of the most prominent or repetitive excerpts aided to generate the five statements that characterize the current personal theme. Table 10 presents the connection of the collective data of afraid of making error theme.

Table 10. The connection of the collective data of afraid of making error theme

\begin{tabular}{lllll}
\hline $\begin{array}{l}\text { Previous Study } \\
\text { Informant No. }\end{array}$ & Type of Document & Excerpt Range & $\begin{array}{l}\text { Current Study } \\
\text { Statement No. }\end{array}$ & Agreement \\
\hline 6 & Interview & $4501-4558$ & & \\
6 & Diary & $1831-2139$ & 16 & $59 \%$ \\
5 & Interview & $3455-3462$ & & \\
2 & Diary & $619-756$ & & $63 \%$ \\
6 & Diary & $1831-2139$ & 17 & \\
5 & Interview & $3455-3462$ & & $74 \%$ \\
4 & Interview & $6552-6785$ & \multirow{2}{*}{18} & \\
6 & Interview & $1831-2139$ & & $68 \%$ \\
4 & Interview & $6552-6785$ & & \\
6 & Diary & $1831-2139$ & 19 & $56 \%$ \\
5 & Interview & $3455-3462$ & & \\
6 & Interview & $4501-4558$ & 20 & \\
6 & Diary & $1831-2139$ & & \\
\hline
\end{tabular}


According to Table 10, the sixteenth statement was matched to the fifth and sixth interviews and the sixth diary of the informants who are more anxious in reading aloud to avoid committing a mistake. 59\% of the respondents agree or strongly agree on the statement which substantiates that students avoid reading aloud in order not to make errors.

The seventeenth statement in sequence arrangement was intently related to the fifth interview and the second and sixth diary of the informants who are very concerned in the accent sub-skill. They are anxious in reading aloud to avoid misreading any word incorrectly. $63 \%$ of the respondents agree or strongly agree on the statement which agrees with fear about reading any word poorly.

The eighteenth statement was equivalent to the fourth and sixth interview of the informants who are highly anxious about reading. They are not only anxious about reading aloud to only avoid misreading, but also they are much anxious towards the appropriate verbalization. They are afraid of making any inaccuracy. $74 \% \%$ of the respondents agree or strongly agree on the statement which confirms that students are more anxious about pronunciation in reading. They are afraid of making even a tiny fault.

The nineteenth statement was follow-on from the fourth and fifth interview and the sixth diary of the informants who are bothered about coming across any new word, which is not common in pronunciation. $68 \% \%$ of the respondents agree or strongly agree on the statement which proves that they are anxious in reading aloud in general to avoid misreading any English term.

The twentieth statement was a resultant of the sixth interview and the sixth diary of the informant who prefers reading silent rather than reading aloud to avoid any kind of observed mistake. $56 \%$ of the respondents agree or strongly agree on the statement which establishes the details of avoiding reading aloud for the same reason previously stated.

Again, third of the informants participated in generating statements, which represent the personal theme from different points of view and that assisted in obtaining the largest percentage of the respondents' agreements on the afraid of making error theme. $64 \%$ of the respondents agree or strongly agree on the theme which ranks it in the first position as a source of English language reading anxiety characterized by personal factors.

As afraid of making error theme was measured as a personal factor, it might be an aspect shared between foreign language anxiety in general and foreign language reading anxiety in particular. That is, foreign language learners who are afraid of reading aloud to avoid committing an observed mistake in pronunciation or misreading any word in the text, they are also more anxious of doing the same in speaking. In the environment where English is used as a foreign language, Turkish students were investigated to confirm that making mistakes or fear of making mistakes were sources of anxiety that influence foreign language learners. In Cubukcu (2007), making mistakes was identified as one of the main sources that causes foreign language anxiety. In another study, fear of making errors in English was found to be a negative effect on the students' anxiety (Celebi, 2009).

Correspondingly, M. Liu (2007) examined Chinese learners' anxiety in oral English classroom. Reflective journals revealed that fear of making mistakes and being laughed at are situations that cause anxiety.

In distant environment learning, Hauck and Hurd (2005) administered a questionnaire as a part of extensive longitudinal study. The purpose of the questionnaire in the initial investigation aimed to provide a description and analysis of the causes of foreign language anxiety. One of the most important causes of anxiety was fear of making mistakes and worrying about accent.

It can be understood that afraid of making errors in the target language is related to the personal factor and can be shared between foreign language anxiety in general and foreign language reading anxiety in particular in any case of the learners' language.

\subsection{Worry about Reading Effects}

Eighteen excerpts from the informants' interviews and diaries were gathered in the previous work and the same number of excerpts of the most prominent or repetitive excerpts facilitated to generate the last six statements that characterize the final theme. Table 11 presents the connection of the collective data of the worrying about reading effect theme. 
Table 11. The connection of the collective data of the worry about reading effect theme

\begin{tabular}{lllll}
\hline Informant No. & Type of Document & Excerpt Range & Statement No. & Agreement \\
\hline 4 & Interview & $4650-4990$ & & \\
6 & Diary & $1930-1973$ & 21 & $68 \%$ \\
2 & Interview & $2989-3123$ & & \\
2 & Interview & $3133-3180$ & & \\
6 & Interview & $3979-4109$ & & $51 \%$ \\
2 & Diary & $874-985$ & 22 & \\
2 & Diary & $986-1095$ & & \\
2 & Diary & $110-1181$ & & $63 \%$ \\
5 & Interview & $4222-4345$ & 23 & \\
2 & Interview & $2989-3123$ & & \\
6 & Diary & $1930-1973$ & & \\
4 & Interview & $4650-4990$ & 24 & $61 \%$ \\
4 & Interview & $5660-5929$ & & \\
5 & Interview & $2093-2223$ & & \\
5 & Interview & $2291-2417$ & 25 & \\
5 & Diary & $725-811$ & & \\
5 & Interview & $2093-2223$ & & \\
2 & Interview & $3133-3180$ & 26 & \\
4 & Interview & $4650-4990$ & & \\
\hline
\end{tabular}

According to Table 11, the twenty-first statement was communicated to the second and forth interview and the sixth diary of the informants who are strenuous on performance. They are anxious about the consequence during the act of reading. For that reason, they reduce the concentration of understanding. $68 \% \%$ of the respondents agree or strongly agree on the statement which ascertains the students' concern in reading aloud is on performance. They are worried about their reading.

The twenty-second statement was directly related to the sixth interview and the second diary of the informants who are also anxious and nervous during the act of reading. In this case, the learners' reflection might be that even though the text was easy; s/he does not think about that due to the demanding anxious situation during the reading act. $51 \%$ of the respondents agree or strongly agree on the statement which supports that students recompense more attention to show high value to the act of reading, which may decrease their understanding even if the message is simple.

The twenty-third statement was similar to the second and fifth interview of the informants who prefer silent reading or reading in private rather than reading aloud. They are anxious before the act of reading. They believe that silent reading helps to comprehend the message due to a slighter amount of interest paid to the performance when reading in front of others. $63 \%$ of the respondents agree or strongly agree on the statement which establishes the information that silent reading lessens the worry about reading effects.

The twenty-forth statement was consequent to the fourth interview and the sixth diary of the informants who are at the same way focusing on the act of reading and particularly in the accent which may create more tense during the act of reading. This tense increases the anxiety during the reading task in the class. It can be a mixture of two anxious situations; afraid of making error and worrying about understanding. $63 \%$ of the respondents agree or strongly agree on the statement which supports the truth that students focus on performance rather than understanding to keep away from provoking anxiety while reading aloud. However, they face some anxiety provoking situation during their concentration on performance due to the personal factor.

The twenty-fifth statement was resembled from the fifth interview and fifth diary of the informant who is nervous during the act of reading because of the doubt that covers his thinking of what he reads. $61 \%$ of the respondents agree or strongly agree on the statement which explains that in most cases, students are not sure what they read because of worrying about reading effects.

The last statement in the instrument was parallel to the second, fourth, and fifth interview of the informants who 
are not only losing some comprehension due to paying more attention to performance during the act of reading but also because they are nervous about losing their text understanding after just finishing the act of reading. $45 \%$ of the respondents agree or strongly agree on the statement which sustains that worrying about reading effects disturbs them and makes them pay less focus. Worries about reading effects were described before, during, and after the act of reading from different views.

One-third of the informants participated in generating statements, which represent the premise from different points of view and that assisted in obtaining the large percentage of the respondents' agreements in the worry about reading effects theme. $59 \%$ of the respondents agree or strongly agree on the theme which ranks it in the second position as a source of English language reading anxiety characterized personal factors.

Kuru-Gonen (2009) found fear of comprehension as a personal factor that creates foreign language reading anxiety; in her study, Turkish students stated that worrying of not understanding English texts creates anxiety provoking situation in reading the target language.

In the case of Chinese learners, Zhao (2009) found reading Chinese as a foreign language is anxiety provoking to most of the students. Approximately, 43\% of 125 sample enrolled in the Chinese course agree or strongly agree on a one FLRAS item which stated, "I'm not sure whether I understand what I am reading in Chinese." Therefore, worrying about reading effects theme was identified as a source of foreign language reading anxiety in the study.

All in all, five themes were generated from the fieldwork of the previous study which is consistent with the previous literature represented in a large percentage in sequential of the current study. These themes were categorized into two aspects; the text features which are related to the nature of texts, and the personal factors which are related to the foreign language learners. The model below represents the underlying factors of the sources of anxiety in reading English at Yarmouk University.

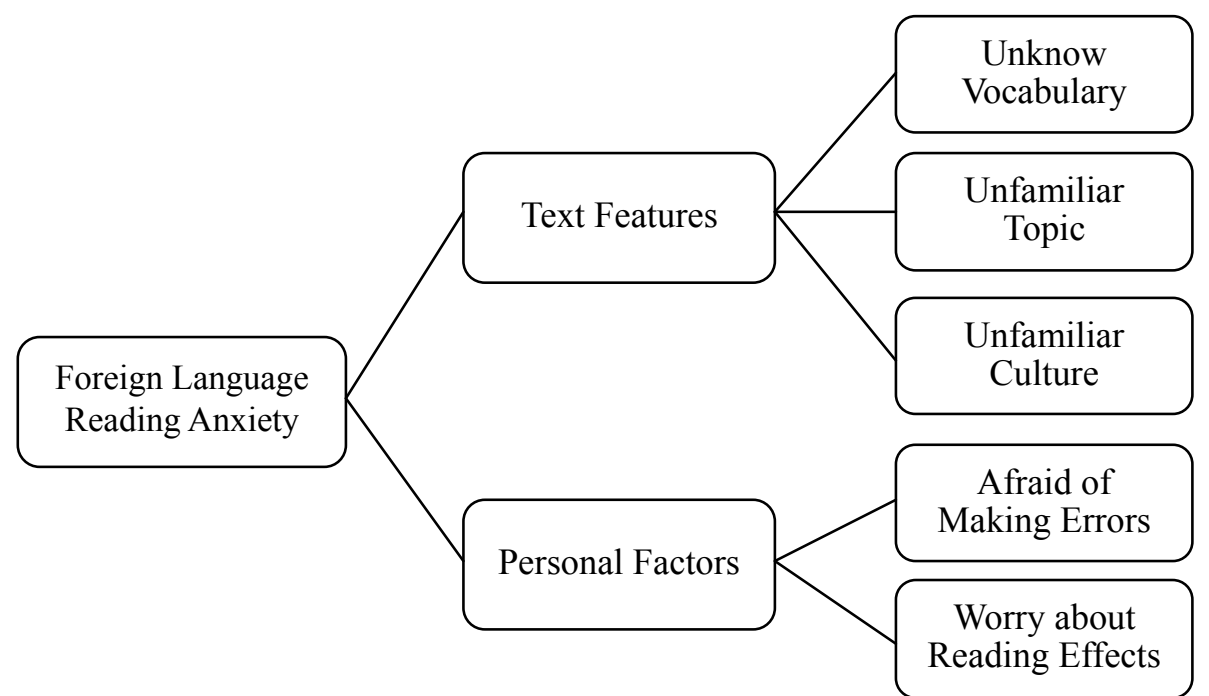

Figure 1. The generated model which represents the sources of English language reading anxiety at Yarmouk University

\section{Conclusions}

There have been many studies conducted on foreign language anxiety in general while few have been conducted on foreign language reading anxiety as a specific skill, and even fewer have been conducted on the sources of foreign language reading anxiety. However, different sources of foreign language reading anxiety were found due to the diversion of the language learner and the target language. According to Saito et al. (1999) foreign language reading anxiety varies according to the target language and specific writing systems. Scrutinizing the literature related to foreign language reading anxiety as a specific skill, almost no study has been conducted on Arabic learners. In fact, no study has been embarked in the Jordanian context. Due to the lack of research on this specific topic, this study was conducted to elicit the underlying factors that contribute to foreign language reading anxiety.

In this context, the mixed method design was carried out to explore and understand the underlying problems and 
factors which contribute to reading anxiety faced by EFL students at Yarmouk University, Jordan. It is a consecutive study of two phases. The first phase of the study was a qualitative exploration of the sources of English language reading anxiety for which semi-structured interview and learners' diaries were collected from six informants at Yarmouk University (Al-Shboul et al., 2013b). The second, quantitative phase was followed up on the qualitative phase for the purpose of expanding and generalizing the results of the generated themes. In the current quantitative phase, a cross-sectional survey for a large number of undergraduate students who were taking Basic English courses was administered.

The findings from the two phases helped to provide a model that explains the sources of reading anxiety in English at Yarmouk University. The reason for collecting qualitative data initially is due to lack of studies has been done in Jordan to explore the sources of English language reading anxiety. Therefore, there was a need to explore the underlying factors of reading anxiety in English. It serves as a preliminary study to guide further studies in this area, and at the same time it is a very helpful step to create a desirable and friendly learning environment.

\subsection{Summary of the Combined Research Findings}

The date gathered basically from the interview and learner diaries were verified in the second phase by the respondents' answers on the questionnaire. Five themes emerged and categorized into two aspects; the personal factors and the text features. These themes were also ranked according to the portion of the occurrences. In both phases, the ranks were similar.

\subsubsection{Text Features}

\section{1) Unknown Vocabulary}

The study verified from the informants and respondents that the largest percentage of students found unknown vocabulary as a source of English language reading anxiety. Students are anxious about the difficult words they encounter, the number of new words as well as the contextual surrounding words of unknown words if they are strange as well, the meanings of the individual words and the translation of the text. This diversity of sides acknowledged the theme as source of English language reading anxiety from the students' perspectives in both studies.

\section{2) Unfamiliar Topic}

The study confirmed from the informants and respondents that the second largest percentage of students found unfamiliar topics as a source of English language reading anxiety. Students are anxious about the odd topics they might read, topics which are not common in their manner, topics which are not related to their studies or topics that they do not have previous knowledge about. These various faces approved the theme as a source of English language reading anxiety from the students' perspectives.

\section{3) Unfamiliar Culture}

The study established from the informants and respondents that unfamiliar culture is a source of English language reading anxiety. Students are worried about the miscellaneous of meanings that their language connotes the sense of translated words, which creates anxiety in reading because of unfamiliar cultural texts which hinder them of deducing the appropriate meaning. In some cases, words are comprehended completely and equally the general message is not. In other cases, students end up translating the text word by word to deduce the message's meaning. This range of features accepted the theme as a source of English language reading anxiety from the students' perspectives.

\subsubsection{Personal Factors}

\section{1) Afraid of Making Errors}

The study verified from the informants and respondents that the largest percentage of students found afraid of making errors as a source of English language reading anxiety caused by the personal factor. Students are anxious about reading aloud to avoid making mistakes. They concern much about pronunciation if they were expected to read in front of their peers and teachers. In most cases, they prefer silent reading to reading aloud. Reading silent is a less anxious situation than reading aloud because one can take as much time as $\mathrm{s} / \mathrm{he}$ needs than reading aloud. This assortment of part confirms the theme as a source of English language reading anxiety from the students' perspectives in both studies.

2) Worry about Reading Effects

The study determined from the informants and respondents that the second largest percentage of students found 
worrying about reading effects as a source of English language reading anxiety caused by the personal factor. Students are anxious and worry about the effect of reading. They focus on the act of reading rather than understanding even when the text is easy for them to understand. To avoid that amount of worry they revealed that they enjoyed reading privately, which, in fact, reduces their obscurity of what they read whether they are worried about recalling the information or their uncertainty of reading. This mix of components reflects the theme as a source of English language reading anxiety from the students' perspectives in both phases.

\section{Implications of the Study}

Based on the findings of the study, the following recommendations can be offered.

First and foremost, the English language teacher should admit the existence of the feeling of anxiety in foreign language reading which affects performance. Furthermore, admitting the sources of foreign language reading anxiety in particular, helps to identify the anxious students in the classroom and deal with them in the first step; the instrument itself might also serve as a practical tool for the students and teachers because it could facilitate the possible causes of anxiety. Sanchez-Herrero and Sanchez (1992) suggested that early detection of the degree of language anxiety helps to facilitate the development of suitable intervention and education strategies for learners. In addition to that, they should facilitate more effective language-learning conditions by making the classroom environment less stressful. Learners are expected to benefit more when educators help to minimize stress and fear and provide a positive learning environment that is motivating to students (Hinton et al., 2008). Reducing foreign language reading anxiety is parallel to motivation, which ultimately improves the performance and increases learning satisfaction. Brown (2007) states that "One of the most important roles of successful teachers is to facilitate high levels of self-efficacy in their students" (p. 156).

Secondly, addressing the sources of anxiety in reading English texts give the English language curriculum designer insight to design materials and activities and even document approaches to support a low filter situation or to bring anxiety down to the minimum according to the needs of the students and to better choose reading materials that contains commonly used vocabulary, familiar topics and cultures, and motivating instructions in order to enhance the students' self-confidence.

Thirdly, in Jordan, most studies in the field of language learning and teaching had a trend focus on the output stage such as teaching strategies, instructional materials and the empirical assessment of their effectiveness, which have led to the maintenance of the belief that English-language learners are poor rely on the outcomes. However, affective variables such as motivation, personality, self-esteem and anxiety particularly in learning English as a foreign language has been almost ignored. Abilities develop overtime; the focus should be on the learning process rather than performance (Hinton et al., 2008).Therefore, this study focuses on the input and process stage. It hopes that this instrument is used to measure the existence of English language reading anxiety at Yarmouk University. It serves as a preliminary phase to cope with foreign language reading anxiety and at the same time mobilize more studies on the affective factors such as foreign language anxiety and particularly foreign language reading anxiety where recent studies have proven the crucial role it plays in foreign language learning and teaching.

\section{Recommendations for Further Research}

There are several recommendations for further research in reading anxiety.

Firstly, it is hoped this study be replicextended using structural Equation Modeling tool to construct validate the underlying factors of English language reading anxiety at Yarmouk University, Jordan.

Secondly, future research could be replicated in different settings in the Middle East countries where Arabic language is the primary language, and English is the foreign language.

Finally, the focus of the next research could be on the ways of reducing foreign language reading anxiety. The researchers in this field might employ instructional technologies or various methods of teachings, which have been proposed to reduce foreign language reading anxiety, followed by experimental research designs to examine the effects of instructional technologies or the various methods of teachings on foreign language reading anxiety diminution.

\section{Acknowledgements}

The research for this paper was financially supported by the Research Management Center, grant no. EDW B13-013-013-0916. In developing the ideas presented here, we would like to thank Dr. Murad M. Al-Shboul for his academic achievement, and the anonymous reviewers for their feedback. 


\section{References}

Al-Shboul, M. M., Ahmad, I. S., Nordin, M. S., \& Rahman, Z. A. (2013a). Foreign Language Anxiety and Achievement: Systematic Review. International Journal of English Linguistics, 3(2). http://dx.doi.org/10.5539/ijel.v3n2p32

Al-Shboul, M. M., Ahmad, I. S., Nordin, M. S., \& Rahman, Z. A. (2013b). Foreign Language Reading Anxiety in a Jordanian EFL Context: A Qualitative Study. English Language Teaching, 6(6), 1-19.

Ary, D., Jacobs, L. C., Razavieh, A., \& Sorensen, C. (2010). Introduction to Research in Education (8th ed.). United States: Wadsworth, Cengage Learning.

Brown, D. (2007). Principles of Language Learning and Teaching (5th ed.). United States of America: Pearson Longman.

Carrell, P. L., Devine, J., \& Eskey, D. E. (Eds.) (2000). Interactive Approaches to Second Language Reading. United Kingdom: Cambridge.

Celebi, S. (2009). Teachers and Students' Views on Anxiety in English Classrooms and Attitudes Towards English. Master, Cukurova University.

Crystal, D. (1997). English as A Global Language. United Kingdom: Cambridge University Press.

Crystal, D. (2004). The Cambridge Encyclopedia of the English Language (2nd ed.). United kingdom: Cambridge University Press.

Cubukcu, F. (2007). Foreign Language Anxiety. Iranian Journal of Language Studies (IJLS), 1(2), 133-142.

Dalkilic, N. (2001). The Role of Foreign Language Classroom Anxiety in English Speaking Courses. ENSTITÜ DERGISI, 8(8), 70-82. Retrieved from http://sosyalbilimler.cukurova.edu.tr/dergi.asp?dosya=366

Gardner, R. C., Tremblay, P. F., \& Masgoret, A. M. (1997). Towards a Full Model of Second Language Learning: An Empirical Investigation. The Modern Language Journal, 81(3), 344-362.

Hauck, M., \& Hurd, S. (2005). Exploring the link Between Language Anxiety and Learner Self-Management in Open Language Contexts. Europian Journal of Open, Distance, and E-Learning, 2.

Hinton, C., Miyamoto, K., \& Della-Chiesa, B. (2008). Brain Research, Learning and Emotions: Implications for Education Research, Policy and Practice. European Journal of Education, 43(1), 87-103.

Horwitz, E. K., Horwitz, M. B., \& Cope, J. (1986). Foreign-Language Classroom Anxiety. Modern Language Journal, 70(2), 125-132.

Huang, H. Y. (2001). Chinese University Students' Anxiety about Reading in English. Doctor of Philosophy, Washington State University, ProQuest. (UMI 3051922).

Jalongo, M. R., \& Hirsh, R. A. (2010). Understanding Reading Anxiety: New Insights from Neuroscience. Early Childhood Education Journal, 37, 431-435.

Kirkpatrick, A. (2007). World Englishes: Implications for International Communication and English Language Teaching. United Kingdom: Cambridge University Press.

Kuru-Gonen, I. (2005). The Sources of Foreign Language Reading Anxiety of Students in a Turkish EFL Context. Master Thesis, Anadolu Universitesi Egitim Bilimleri Enstitusu.

Kuru-Gonen, I. (2007). L2 Reading Anxiety: Exploring the Phenomenon. In B. W. K. (Ed.), JALT2006 KITAKYUSHU Community, Identity, Motivation. Tokyo: JALT.

Kuru-Gonen, I. (2009). The Sources of Foreign Language Reading Anxiety of Students in a Turkish EFL Context. Paper presented at the 5th WSEAS/IASME International Conference on EDUCATIONAL TECHNOLOGIES (EDUTE' 09), Spain.

Lin, G. H. C. (2009). An Exploration into Foreign Language Writing Anxiety from Taiwanese University Students' Perspectives. Paper presented at the NCUE Fourth Annual Conference on Language, Teaching, Literature, Linguistics, Translations and Interpretation. Retrieved from http://www.eric.ed.gov/ERICWebPortal/contentdelivery/servlet/ERICServlet?accno=ED506178

Liu, M. (2007). Anxiety in Oral English Classroom: A Case Study in China. Indonesian Journal of English Language Teaching, 3(1), 119-137.

Liu, Y. H. (2011). Syntactic Differences and Foreign Language Reading Anxiety: An Investigation of Taiwanese University Students. Doctor of Philosophy, The Ohio State University. 
Macintyre, P. D. (1995). How Does Anxiety Affect Second Language Learning? A Reply to Sparks and $\begin{array}{lllll}\text { Ganschow. The Modern } & \text { Language Journal, }\end{array}$ http://dx.doi.org/10.1111/j.1540-4781.1995.tb05418.x

Marwan, A. (2007). Investigating Students' Foreign Language Anxiety. Malaysian Journal of ELTT Research, 3, 37-55.

Marwan, A. (2008). The Exploration of Factors Treggering Foreign Language Anxiety: Learners' Voice. TEFLIN Journal, 19(2), 119-126.

Merc, A. (2011). Sources of Foreign Language Students Teacher Anxiety: A Qualitative Inquiry. Turkish Online Journal of Qualitative Inquiry, 2(4), 80-94.

Miyanaga, C. (2007). Anxiety, Strategies, Motivation, and Reading Proficiency in japanese Univesities EFL Learners. Doctoral Dessertation, The Temple University Graduate Broad, ProQuest. (UMI 3268181).

Ohata, K. (2005). Potential Sources of Anxiety for Japanese Learners of English: Preliminary Case Interviews with Five Japanese College Students in the U.S. Teaching English as a Second or Foreign Language, 9(3).

Razi, S. (2004, September). The Effect of Cultural Schema and Reading Activities on Reading Comprehension. Paper presented at the First International Online Conference on Second and Foreign Language Teaching and Research, United States.

Saito, Y., Horwitz, E. K., \& Garza, T. J. (1999). Foreign language reading anxiety. Modern Language Journal, 83(2), 202-218.

Sanchez-Herrero, S. A., \& Sanchez, M. D. P. (1992). The Predictive Validation of an Instrument Designed to Measure Student Anxiety in Learning a Foreign Language. Education and Psychological Measurment, 52, 961-966. http://dx.doi.org/10.1177/001364492052004019

Sellers, V. D. (2000). Anxiety and reading comprehension in Spanish as a foreign language. Foreign Language Annals, 33(5), 512-521.

Tanveer, M. (2007). Investigation of the Factors that cause Language Anxiety for ESL-EFL Learners in Learning Speaking Skills and the Influence it Casts on Communication in the Target Language. Master Thesis, University of Glasgow.

Teddlie, C., \& Tashakkori, A. (2009). Foundations of Mixed Methods Research: integrating quantitative and qualitative approaches in the social and behavioral sciences. Sage Publications Inc.

Toth, Z. (2011). Foreign Language and Advanced EFL Learners: An Interview Study. WoPaLP, 5, 39-57.

Walker, E. A. (1997). Foreign Language Anxiety in Hong Kong Secondary Schools: Its Relationship with the Age-Related Factors, School form and Self-Perception. PhD Thesis, University of Hong kong, Creative Commons: Attribution 3.0 Hong Kong License.

William, K. E., \& Andrade, M. R. (2008). Foreign Language Learning Anxiety in Japanese EFL University Classes: Causes, Coping and Locus of Control. Electronic Journal of Foreign Language Teaching, 5(2), 181-191.

Wu, H. J. (2011). Anxiety and Reading Comprehension Performance in English as a Foreign Language. Asian EFL Journal, 13(2), 273-307.

Yan, J. X., \& Horwitz, E. K. (2008). Learners' Perceptions of How Anxiety Interacts with Personal and Instructional Factors to Influence their Achievement in English: A Qualitative Analysis of EFL Learners in China. Language Learning, 58(1), 151-183.

Zhao, A. (2009). Foreign Language Reading Anxiety: Investigating English-Speaking University Students Learning Chinese as a Foreign Language in the United States. Doctor of Philosophy, The Florida State University.

\section{Copyrights}

Copyright for this article is retained by the author(s), with first publication rights granted to the journal.

This is an open-access article distributed under the terms and conditions of the Creative Commons Attribution license (http://creativecommons.org/licenses/by/3.0/). 